Research Article

\title{
Energy Dissipation and Particle Size Distribution of Granite under Different Incident Energies in SHPB Compression Tests
}

\author{
Fengqiang Gong $\mathbb{D}^{1,2}$ Hangyu Jia, ${ }^{1}$ Zongxian Zhang, ${ }^{3}$ Jian Hu, ${ }^{1}$ and Song Luo ${ }^{1}{ }^{1}$ \\ ${ }^{1}$ School of Resources and Safety Engineering, Central South University, Changsha 410083, China \\ ${ }^{2}$ School of Civil Engineering, Southeast University, Nanjing 211189, China \\ ${ }^{3}$ Oulu Mining School, University of Oulu, Oulu, Finland \\ Correspondence should be addressed to Fengqiang Gong; fengqiangg@126.com
}

Received 24 August 2020; Revised 7 October 2020; Accepted 1 November 2020; Published 18 November 2020

Academic Editor: Xuesheng Liu

Copyright ( 92020 Fengqiang Gong et al. This is an open access article distributed under the Creative Commons Attribution License, which permits unrestricted use, distribution, and reproduction in any medium, provided the original work is properly cited.

\begin{abstract}
To investigate energy dissipation and particle size distribution of rock under dynamic loads, a series of dynamic compression tests of granite specimens were conducted using a conventional split-Hopkinson pressure bar (SHPB) device with a high-speed camera. The experimental results show that the dissipated energy increases linearly with an increasing incident energy, following two different inclined paths connected by a critical incident energy, and the linear energy dissipation law in the dynamic compression test has been confirmed. This critical incident energy was found to be $0.29-0.33 \mathrm{MJ} / \mathrm{m}^{3}$. As the incident energy was smaller than the critical incident energy, the rock specimens remained unruptured after the impact. When the incident energy was greater than the critical incident energy, the rock specimens were ruptured or fragmented after the impact. In addition, the experimental results indicate that the dissipated energy and energy consumption ratio of a rock specimen, either unruptured or fragmented, increase with an increasing strain rate. Furthermore, it was found that fragment sizes at each mesh decrease with an increasing incident energy; that is, fragmentation becomes finer as incident energy increases.
\end{abstract}

\section{Introduction}

Rock structures are frequently subjected to dynamic loads from rock drilling, rock blasting, rock bursts, and seismic events or earthquakes [1-4]. Under dynamic loads, rock damage or fracture may occur and energy consumption happens [5-7]. Accordingly, it is of importance to investigate energy dissipation in the process of rock fracture [8-15]. Under static loads, experimental studies have confirmed that the deformation and failure of rock is a process of energy input, dissipation, and release. Gao et al. [16] investigated the characteristics of energy storage and dissipation of coal under one-time cyclic compression load. Gong et al. [17-19] found the linear energy storage and dissipation laws of rock materials in uniaxial compression tests or tension-type failure tests. Under dynamic loads, energy consumption has been experimentally studied for many decades using the split-Hopkinson pressure bar
(SHPB) or tensile bar (SHTB). Among the previous investigators, Lundberg [20] and $\mathrm{Li}$ [21] through dynamic compression strength tests discovered that the energy absorbed by rock samples is usually less than $50 \%$ of the total input energy. Zhang et al. [22-24] by means of dynamic fracture tests found that the totally absorbed energy by rock increases with an increasing loading rate, but the energy efficiency decreases with an increasing loading rate. $\mathrm{Li}$ et al. [25] carried out dynamic compression tests on Bukit Timah granite and concluded that fractured specimens absorb more energy than unbroken ones and energy absorption per unit volume of rock increases linearly with increasing strain rates. Hong et al. [26] also conducted dynamic compression tests on granite, sandstone, and limestone and found that the average size of rock specimens decreases with the increase of the energy consumption per unit volume. Deng et al. [27] conducted dynamic uniaxial compressive tests on granite and 
sandstone and obtained a similar result as Hong et al. [26] did. Gong and $\mathrm{Hu}$ [28] found the dynamic linear energy dissipation law in the dynamic Brazilian disc tests on red sandstone.

The above description indicates that the previous studies have achieved important results of energy dissipation during rock fracture under dynamic loads. However, some gaps still exist. For example, (1) energy dissipation of unruptured specimens after impact compression testing has been seldom investigated and (2) the impact of incident energy on particle size distribution lacks a series of experimental studies. Based on the above background, this study investigated the energy dissipation of granite under dynamic compression by using the SHPB system with a high-speed camera filming the rock failure process. After the SHPB tests, all particles/fragments from granite specimens were collected, sieved, and analyzed, and the relation between incident energy and particle size was established.

\section{Experimental Methods}

2.1. SHPB Test System. This study employed the SHPB system which has been widely used in dynamic rock strength tests, dynamic rock fracture tests, and stress wave propagation tests [29-36]. As the SHPB system is used in measuring rock strengths and fracture toughness, two conditions should be satisfied: one-dimensional loading condition and stress equilibrium condition at the two ends of the rock specimen. The first condition means that a stress wave on each cross section of elastic bars always is kept as a planar wave. The second condition states that the stresses on both ends of the specimen are approximately equal before or when the specimen is failed.

As shown in Figure 1 (Gong et al. $[35,37]$ ), the air gun can apply different impact loads to the testing system by adjusting the air pressure and the air pressure of the test is $0.35 \sim 0.85 \mathrm{MPa}$. The incident bar and transmitted bar were made of $40 \mathrm{Cr}$ alloy steel with a diameter of $50 \mathrm{~mm}$, a density of $7.81 \mathrm{~g} / \mathrm{cm}^{3}$, and a longitudinal wave velocity of $5410 \mathrm{~m} / \mathrm{s}$. The lengths of the incident bar and transmitted bar were $2.0 \mathrm{~m}$ and $1.5 \mathrm{~m}$, respectively. A spindle-shaped bullet was used to produce a half-sine wave.

To clearly observe the deformation and fracture characteristics of a rock specimen, a high-speed camera was used to record the whole loading and fracturing process. The camera took 72,000 frames per second (fps); that is, one photo took $13.89 \mu \mathrm{s}$. During a test, a glass box was placed surrounding the rock specimen. After the test, fragments of the fragmented granite specimen were collected. Then, the collected fragments were sieved in an order from large to small mesh sizes. After then, the fragments at each mesh size were weighed by using a high-sensitivity electronic scale with an accuracy of $0.01 \mathrm{~g}$.

2.2. Testing Principle. In the SHPB system in Figure 1, the stress $\sigma(t)$, strain $\mathcal{E}(t)$, and strain rate $\dot{\varepsilon}(t)$ at time $t$ of the rock specimen can be obtained by the following formulas:

$$
\begin{aligned}
& \sigma(t)=\frac{\mathrm{AE}}{2 A_{\mathrm{S}}}\left[\varepsilon_{\mathrm{I}}(t)+\varepsilon_{\mathrm{R}}(t)+\varepsilon_{\mathrm{T}}(t)\right], \\
& \varepsilon(t)=\frac{C}{L_{\mathrm{S}}} \int_{0}^{t}\left[\varepsilon_{\mathrm{I}}(t)-\varepsilon_{\mathrm{R}}(t)-\varepsilon_{\mathrm{T}}(t)\right] \mathrm{d} t, \\
& \dot{\varepsilon}(t)=\frac{C}{L_{\mathrm{S}}}\left[\varepsilon_{\mathrm{I}}(t)-\varepsilon_{\mathrm{R}}(t)-\varepsilon_{\mathrm{T}}(t)\right],
\end{aligned}
$$

where $A$ and $E$ are the cross-sectional area and Young's modulus of the bars, respectively; $C$ is the one-dimensional longitudinal stress wave velocity of the bars; $A_{\mathrm{S}}$ and $L_{\mathrm{S}}$ are the cross-sectional area and length of rock specimen, respectively; $\varepsilon_{\mathrm{I}}(t), \varepsilon_{\mathrm{R}}(t)$, and $\varepsilon_{\mathrm{T}}(t)$ are the incident strain, reflected strain, and transmitted strain at the $t$, respectively.

The incident energy $E_{\mathrm{I}}(t)$, reflected energy $E_{\mathrm{R}}(t)$, and transmitted energy $E_{\mathrm{T}}(t)$ can be obtained by the following formulas (e.g., Lundberg [20]):

$$
\begin{aligned}
& E_{\mathrm{I}}(t)=\operatorname{ECA} \int_{0}^{t} \varepsilon_{I}^{2}(t) \mathrm{d} t \\
& E_{\mathrm{R}}(t)=\operatorname{ECA} \int_{0}^{t} \varepsilon_{R}^{2}(t) \mathrm{d} t, \\
& E_{\mathrm{T}}(t)=\operatorname{ECA} \int_{0}^{t} \varepsilon_{T}^{2}(t) \mathrm{d} t .
\end{aligned}
$$

In the SHPB test, the absorbed energy is often used to represent the energy dissipated during the impact of the rock specimen. In fact, the calculated energy absorbed by the rock specimen is equal to the energy dissipated in the impact process of the rock specimen [28]. The meaning of the dissipation energy in the dynamic compression specimen is the same as in the static test; that is, it is used for the failure and plastic deformation of the rock specimen during the compression process [38].

Thus, the dissipated energy by the rock specimen $E_{\mathrm{A}}(t)$ can be calculated by

$$
E_{\mathrm{A}}(t)=E_{\mathrm{I}}(t)-E_{\mathrm{R}}(t)-E_{\mathrm{T}}(t)
$$

The energy $E_{\mathrm{A}}(t)$ is dissipated in different components such as (1) fracture and damage energy $E_{\mathrm{FD}}$ used in crack extension and crack branching, (2) kinetic energy $E_{\mathrm{K}}$ used in translation and rotation of fragments, and (3) other energies $E_{\mathrm{O}}$ consumed in friction, heating, and other forms of energy (Zhang [24]); that is,

$$
E_{\mathrm{A}}=E_{\mathrm{FD}}+E_{\mathrm{K}}+E_{\mathrm{O}}
$$

2.3. Specimen Preparation. The Changsha granite was selected to conduct dynamic compression tests due to its better integrity and homogeneity than many other rocks. All specimens were cored from one big $(1 \mathrm{~m} \times 1 \mathrm{~m} \times 1 \mathrm{~m})$ granite block with invisible geological structures. The specimens used in the test are 18. The specimen ID was organized in the form of "G-a," wherein " $G$ " represents the granite and "a" represents the specimen number. The specimens were manufactured into cylinders with a diameter and a height of $50 \mathrm{~mm}$, as shown in Figure 2. The tolerance of evenness and 


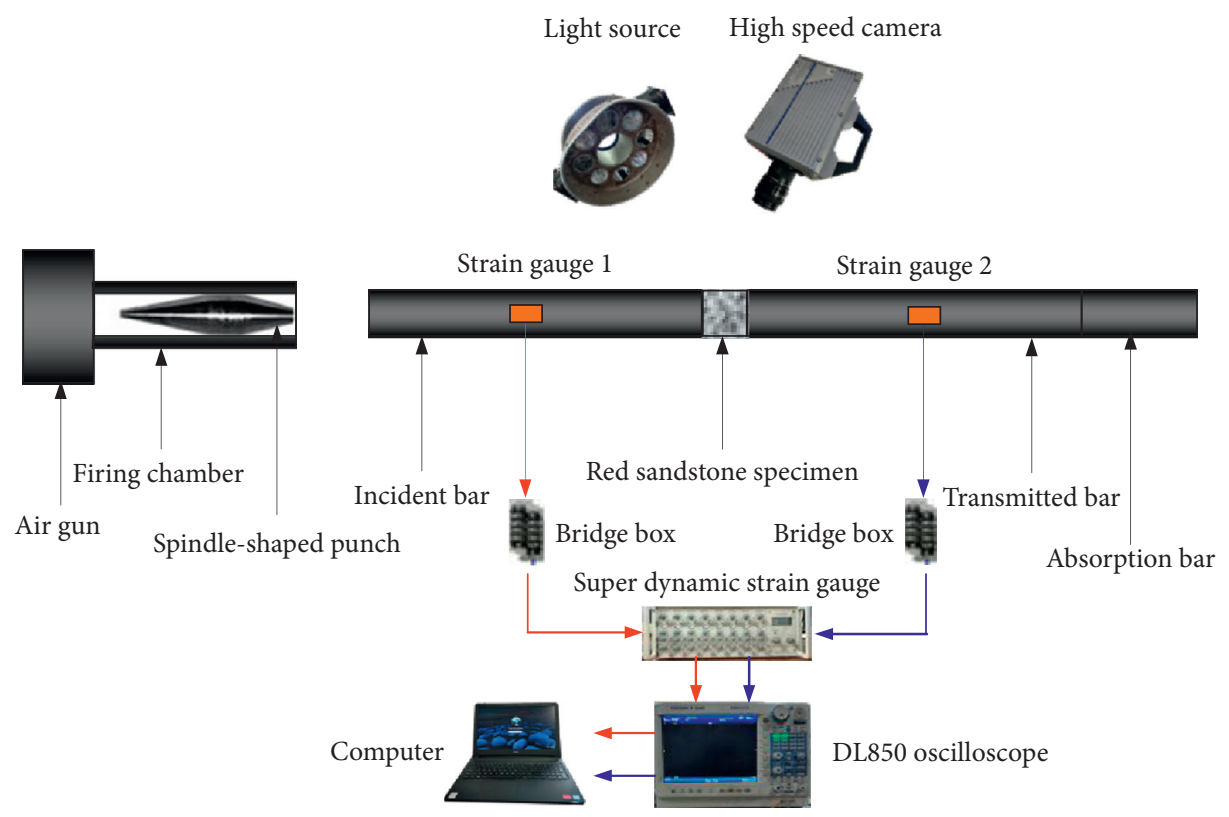

FIGURE 1: Diagram of the conventional SHPB testing system (Gong et al. [35, 37]).

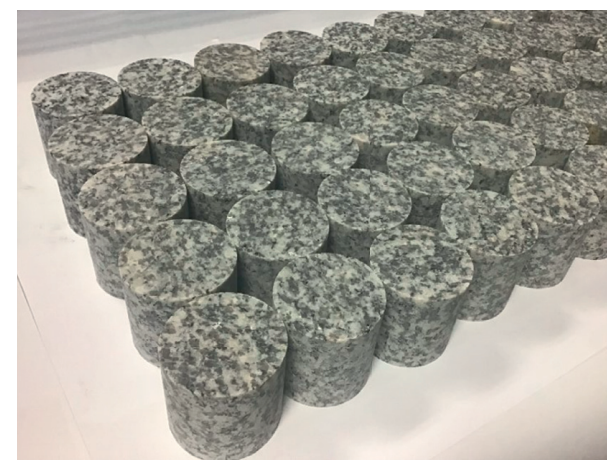

Figure 2: Processed specimens of granite.

nonparallelism of the specimen ends were less than $0.02 \mathrm{~mm}$. The two-end surfaces of each specimen were coated with lubricant before the testing. The mechanical parameters of the granite are listed in Table 1.

2.4. Preparation of SHPB System before Formal Tests. Prior to formal tests, a trial experiment without rock specimen was performed to check the stability of the testing system. Figure 3(a) shows two stable and almost identical incident and transmitted waves, indicating that the wave measurement of the SHPB system is reliable for the formal tests. To ensure a dynamic stress equilibrium mentioned above, a trial test with one specimen was carried. Figure 3(b) shows the measured waves in the incident bar and the transmitted bar. Figure $3(\mathrm{c})$ indicates that the sum of the incident and reflected stress waves agrees well with the transmitted, meaning that the stresses on both ends of the specimen are approximately equal during dynamic loading.

\section{Test Results}

3.1. Stress-Strain Curves and Characteristics of Deformation and Failure. The stress-strain curves of 6 representative granite specimens under different incident energies are shown in Figure 4 . These curves can be divided into three different types, as follows:

Type I: the strain decreases immediately after the peak stress. As indicated by the curves of specimens G-1 and G-3, an elastic rebound immediately occurs in the stress-strain curves after the peak stress is reached. This elastic rebound is similar to the unloading process of a rock specimen in static rock compression tests.

Type II: the peak stress strain first increases for a while and then decreases, as shown in the stress-strain curves of specimens G-8 and G-9.

Type III: the peak stress strain increases until the specimen is completely fragmented, as indicated in the curves of specimens G-15 and G-17.

It was found that the types of stress-strain curves are closely associated with the characteristics of deformation and failure modes of the rock specimens. As shown in Figure 5, the specimens G-1 and G-3 of type I remained intact and they were still able to bear load after impact (Figure 5(a)). This type is called unruptured state in which no fracture happens. Type II specimens G-8 and G-9 were fragmented by one or multicracks but they could still bear a load in the axial or loading direction after impact (Figure 5(b)). This type is called ruptured state. Type III specimens G-15 and G-17 were completely destroyed into numerous fragments and fine particles, and the specimens could not bear any load at all after impact (Figure 5(c)). This type is named fragmented state.

3.2. Failure Process. Figure 6 shows the failure processes of the three-type granite specimens during impact tests. The high-speed camera is connected with the oscilloscope. The oscilloscope will trigger the high-speed camera by recording 
TABle 1: Mechanical parameters of granite under static load.

\begin{tabular}{lccc}
\hline Density $\left(\mathrm{kg} / \mathrm{m}^{3}\right)$ & $P$-wave velocity $(\mathrm{m} / \mathrm{s})$ & Elastic modulus $(\mathrm{GPa})$ & Uniaxial compressive strength $(\mathrm{MPa})$ \\
\hline 2631 & 4930 & 63.98 & 143 \\
\hline
\end{tabular}

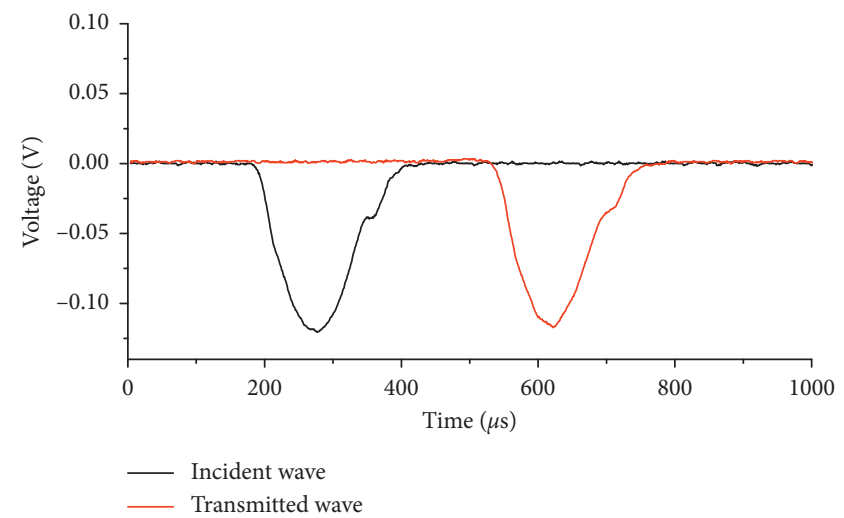

(a)

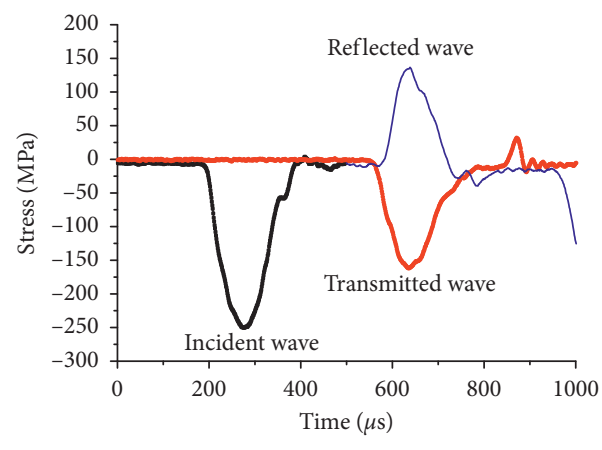

(b)

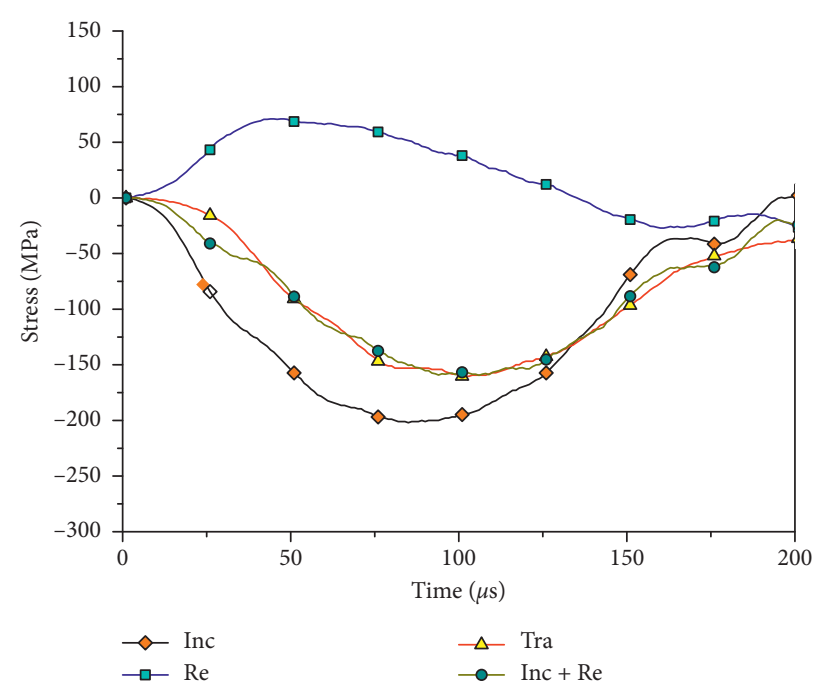

(c)

FIGURE 3: Trial experiment and dynamic stress equilibrium. (a) Signals collected by data acquisition system during trial experiment without specimen. (b) Typical stress wave pattern of a tested rock specimen. (c) Dynamic stress equilibrium (Inc: incident wave, Re: reflected wave, and Tra: transmitted wave).

the stress wave signal of the strain gauge on the incident bar. In order to determine the synchronization between the time of each photo taken by the camera and the loading process of the specimen, it is necessary to calculate the time that the stress wave propagates from the strain gauge to the specimen on the incident bar. The distance measured between the strain gauge and the specimen is $0.75 \mathrm{~m}$, and the propagated speed of stress wave in the incident bar is $5450 \mathrm{~m} / \mathrm{s}$. Therefore, the propagated time of incident wave transmitted from the strain gauge to the end of the specimen is $137.61 \mu \mathrm{s}$. Since the high-speed camera takes a photo every $13.89 \mu \mathrm{s}$, the 11 th one taken can be considered as the initial time of stress wave transmitted to the specimen. In this way, the time matching between the photos taken by the high-speed camera and the stress loading process is realized.
As shown in Figure 6(a), when the incident energy was at a low level, type I specimen G-1 remained intact at time $791.73 \mu \mathrm{s}$. The energy dissipated by the specimen was low, due to partly the low incident energy and partly the elastic rebound. Furthermore, the dissipated energy was possibly consumed in producing damage, microcracks, and so on in the specimen. At high-level incident energy, type II and III specimens G-8 and G-13 were fractured as illustrated in Figures 6(b) and 6(c). At $194.46 \mu \mathrm{s}$, some cracks were created in the two specimens. The movement/flight of one fragment can be seen in Figure 6(c) at $791.73 \mu \mathrm{s}$.

To study the crack propagation process of specimens in more detail, the stress-time and stress-strain curves of specimens G-8 and G-13 and the corresponding images taken by the high-speed camera are shown in Figure 7. 


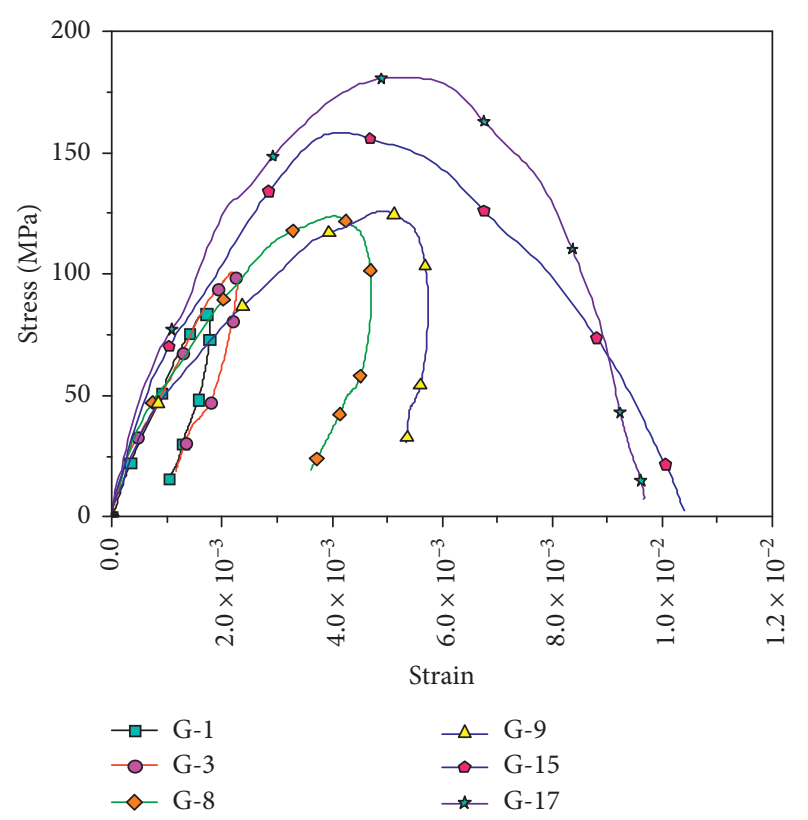

Figure 4: Three typical dynamic stress-strain curves.

According to the curves and photos, the failure processes of the specimens can be approximately divided into four stages: (1) linear deformation stage (O-A) in which stress-strain relation is approximately linear, (2) nonlinear deformation stage (A-B) in which cracks in and on the rock specimens are initiated and they start to propagate, (3) rapid crack propagation stage (B-C) in which cracks rapidly propagate but they do not make rock specimens broken, and (4) failure stage (C-D-E) in which rock specimens are completely fragmented into two or many pieces. To determine the boundary between the two stages, the photos close to each boundary were examined carefully.

Specimen G-8 looks intact during the first stage (O-A) from the pictures. Two distinct cracks appeared from both upper ends of the specimen during the second stage (A-B) and extended to the middle of the specimen in the stage that includes the rapid crack propagation stage and the failure stage (B-E).

Similar to G-8, specimen G-13 looks intact in the O-A stage. Small cracks were generated at the top of the specimen in A-B stage and extended to the middle of the specimen in the form of tensile and shear failure in B-C stage. During a short period of time, cracks on the specimen coalesced, forming a macrofracture surface and the specimen lost its bearing capacity (C-D-E). Based on the pictures, some cracks on the G-13 and G-8 specimens were initiated at 55-83 microseconds and crack extension happened after the peak stress peak was attained (see this from Figures 8(a) and $8(c))$.

3.3. Energy Dissipation Characteristic. The test results for the incident energy and dissipated energy of the three-type specimens are presented in Table 2. To study the energy efficiency of the specimens, the energy consumption ratio was defined as the ratio of the energy dissipated by a specimen to the incident energy. It was found that as incident energy is greater than $106 \mathrm{~J}$ and smaller than $120 \mathrm{~J}$, a rock specimen is ruptured; as incident energy is greater than $120 \mathrm{~J}$, a specimen is usually fragmented. The former (energy $106 \mathrm{~J}$ ) is defined as critical incident energy corresponding to ruptured state, while the latter (energy $120 \mathrm{~J}$ ) is defined as the critical incident energy corresponding to fragmented state. As these energies are divided by the volume of the specimens, they are defined as specific critical incident energy corresponding to ruptured state and fragmented state, respectively. Their units are $\mathrm{J} / \mathrm{m} 3$.

As shown in Figure 9, there are two different relations between dissipated energy and incident energy, dependent on the rock failure mode. For the specimens that remain in unruptured state after impact, the relation between dissipated energy and incident energy can be expressed by

$$
E_{\mathrm{AU}}=k_{1} E_{\mathrm{I}}+c_{1}\left(E_{\mathrm{I}}<E_{\mathrm{CIR}}\right),
$$

where $E_{\mathrm{AU}}$ is the dissipated energy of a specimen in unruptured state, $k_{1}$ is a coefficient, $c_{1}$ is a constant, and $E_{\mathrm{CIR}}$ is the critical incident energy corresponding to ruptured state. As incident energy is greater than $E_{\mathrm{CIR}}$, rock will be certainly fractured. This linear energy dissipation characteristic is similar to the linear energy dissipation law of rock in static load test $[17,19]$.

Similarly, the relation between dissipated energy and incident energy in fragmented state can be described by

$$
E_{\mathrm{AF}}=k_{2} E_{\mathrm{I}}+c_{2}\left(E_{\mathrm{I}}>E_{\mathrm{CIF}}\right) \text {, }
$$

where $E_{\mathrm{AF}}$ is the dissipated energy of specimens in the fragmented state, $k_{2}$ is coefficient, and $c_{2}$ is a constant. $E_{\mathrm{CIF}}$ is the critical incident energy corresponding to fragmented state.

Figure 9 indicates that the dissipated energy increases much faster in the fragmented state than in the unruptured state.

3.4. Relation between Strain Rate and Energy Dissipation. As shown in Figure 8 based on Table 2, it can be seen that incident energy and dissipated energy increase with increasing strain rate, at two different speeds and at two states, unruptured state and fragmented one. Obviously, the speeds corresponding to incident energy and dissipated energy are higher in the fragmented state than in the unruptured state. In addition, Figure 8(c) shows that the energy consumption ratio increases with increasing strain rate, too. Differently, the energy consumption ratio increases faster in the unruptured specimens than in the fragmented one.

3.5. Size Distribution of Fragmented Specimens. Figure 10 shows the fragments at 11 mesh sizes of 5 fragmented specimens. Figure 11 presents the sieving results. The 11 mesh sizes and the sieving results are also shown in Table 3. In addition, even if a glass box was used to keep rock fragments inside during each test, it is inevitable that some fragments were ejected from the gap between the box and the test equipment, resulting in the loss of some fragments, 

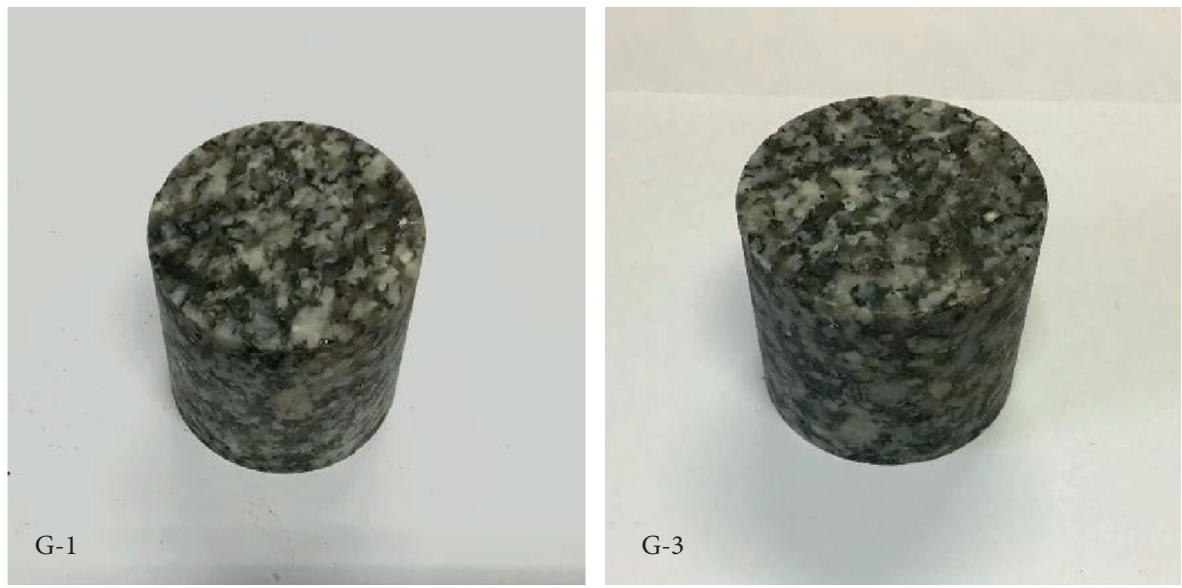

(a)
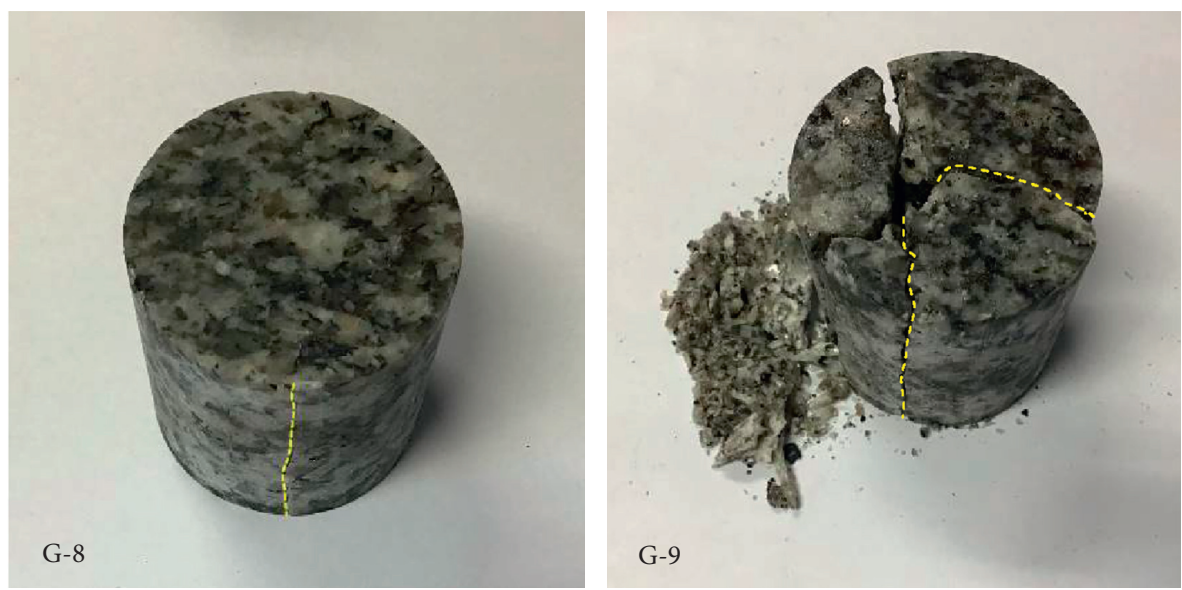

(b)
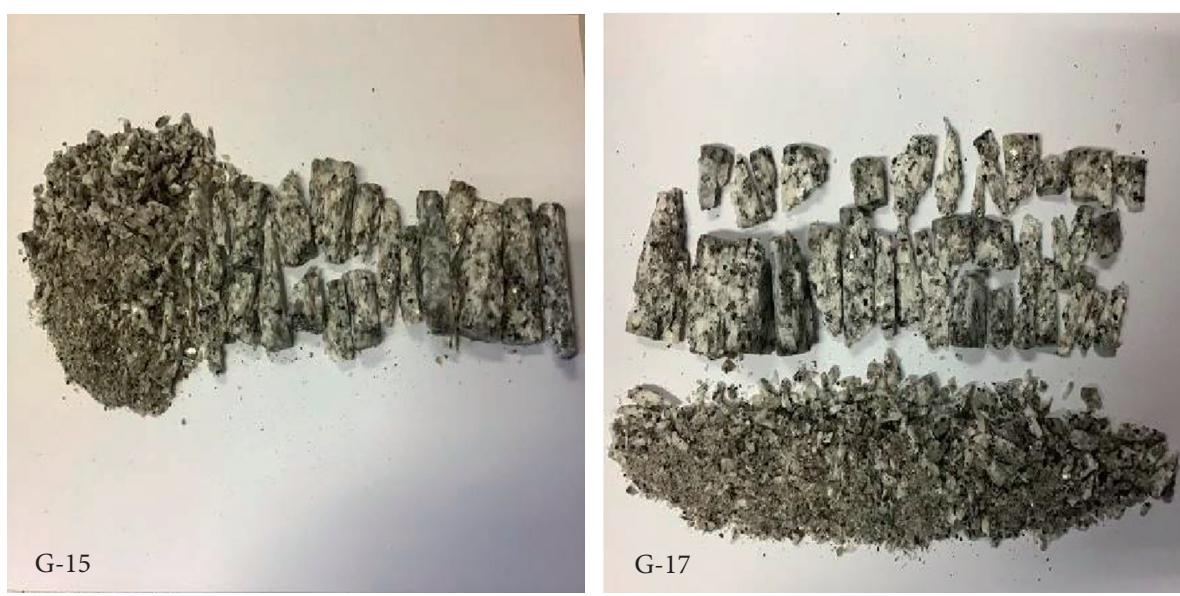

(c)

Figure 5: Granite specimens after impact tests. (a) Type I (unruptured state) specimens G-1 and G-3. (b) Type II (ruptured state) specimens G-8 and G-9. (c) Type III (fragmented state) specimens G-15 and G-17.

especially fine particles. In order to determine such weight loss, the masses of each specimen before and after testing were weighed and the results are shown in Table 4, indicating that the weight loss varies from $0.6 \%$ to $5.4 \%$.

Figure 11 shows that fragmentation becomes finer as incident energy increases; that is, the greater the incident energy is, the finer fragmentation is. This result can be also seen from the photos in Figure 10.

To study the influence of incident energy on the cumulative mass passing of the specimens, the three relations between incident energy and particle/mesh size were established for three accumulated mass passings, $100 \%, 50 \%$, 

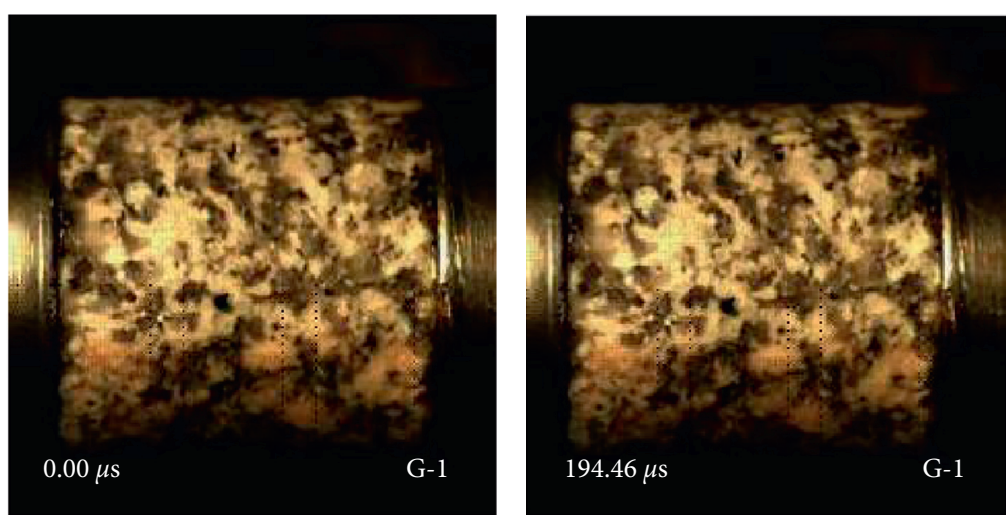

(a)
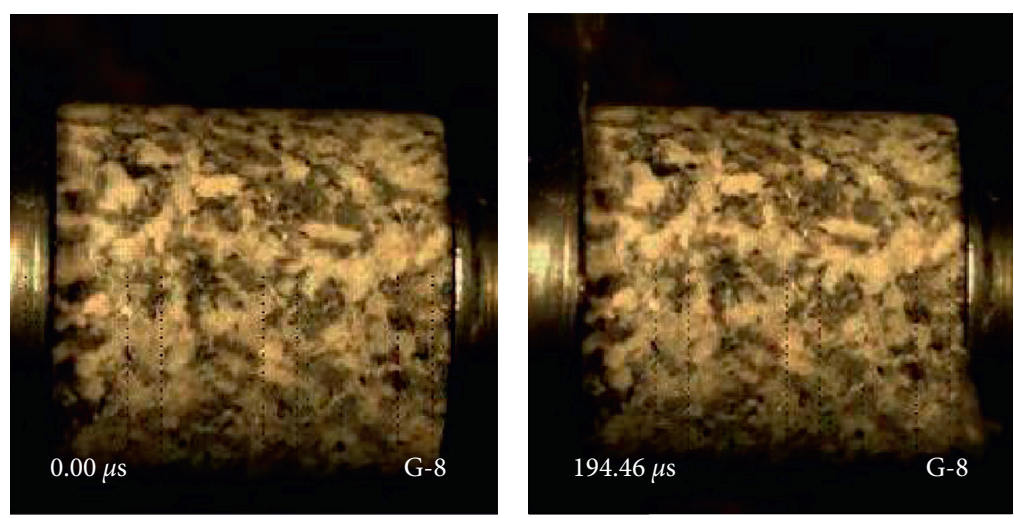

(b)
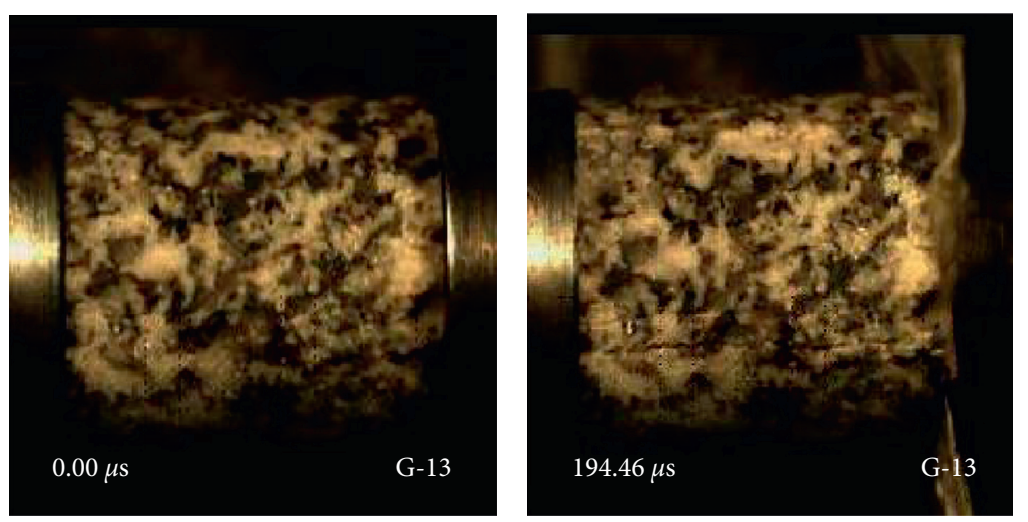

(c)
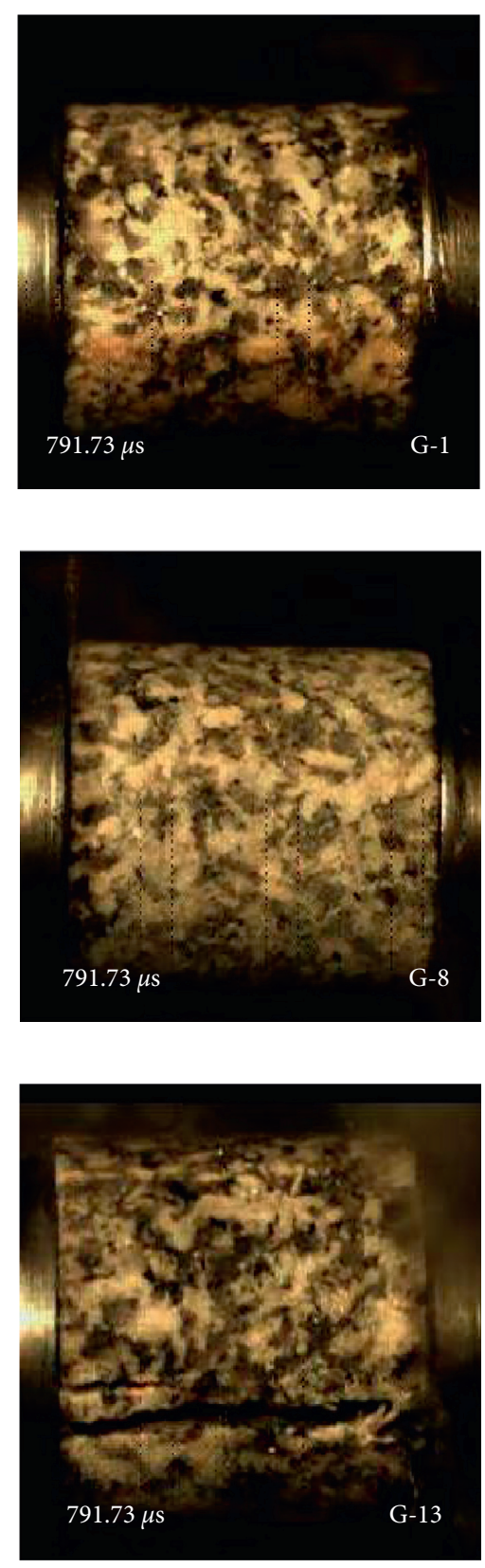

FIGURE 6: Failure processes of specimens in types I, II, and III.

and 5\%, as shown in Figure 12. It can be seen that when the incident energy was $296.92 \mathrm{~J}$, all rock fragments passed through the sieve with a mesh size of $25 \mathrm{~mm}$; that is to say, all the fragments were less than $25 \mathrm{~mm}$. With the increase of incident energy from $158.61 \mathrm{~J}$ to $296.92 \mathrm{~J}$, the particle sizes at $50 \%$ mass passing are $25 \mathrm{~mm}, 25 \mathrm{~mm}, 20 \mathrm{~mm}, 8 \mathrm{~mm}$, and $6 \mathrm{~mm}$, respectively. The particle sizes at 5\% mass passing are $8 \mathrm{~mm}, 1.25 \mathrm{~mm}, 1.25 \mathrm{~mm}, 0.6 \mathrm{~mm}$, and $0.28 \mathrm{~mm}$, respectively. Figure 12 indicates that (1) at $100 \%$ mass passing the particle size is a constant as incident energy increases from $159 \mathrm{~J}$ to $263 \mathrm{~J}$. As incident energy increases from $263 \mathrm{~J}$, the particle size decreases, meaning that $263 \mathrm{~J}$ is a critical value for incident energy; that is, as incident energy is greater than
$263 \mathrm{~J}$, the maximum particle size is reduced. In reality, the particle size at $100 \%$ means the biggest fragment or boulder. (2) At $50 \%$ mass passing, the particle size is constant as incident energy is equal to or smaller than $184 \mathrm{~J}$. After this energy, the particle size decreases quickly before incident energy reaches $263 \mathrm{~J}$. After incident energy reaches $263 \mathrm{~J}$, the particle size decreases slowly with increasing incident energy. Notice that $50 \%$ mass passing may represent average fragment size in practical rock fragmentation by either blasting or mechanical rock fracture under dynamic loads to a great extent. (3) At 5\% mass passing, the particle size starts to decrease fast from the smallest incident energy $159 \mathrm{~J}$ to $184 \mathrm{~J}$. After $184 \mathrm{~J}$, the particle size decreases slowly with 


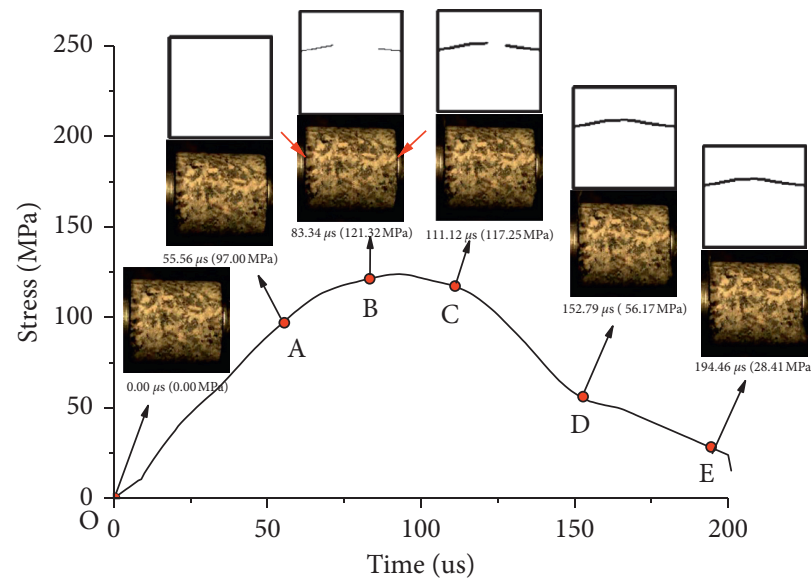

(a)

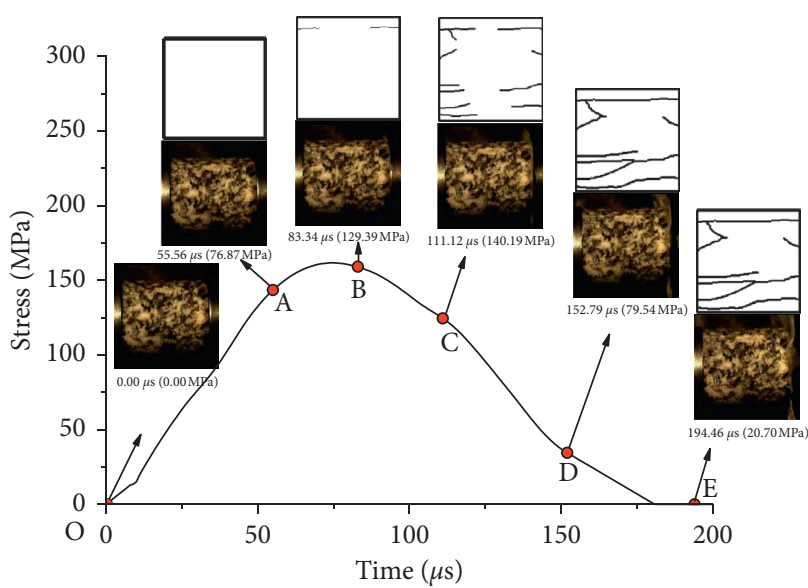

(c)

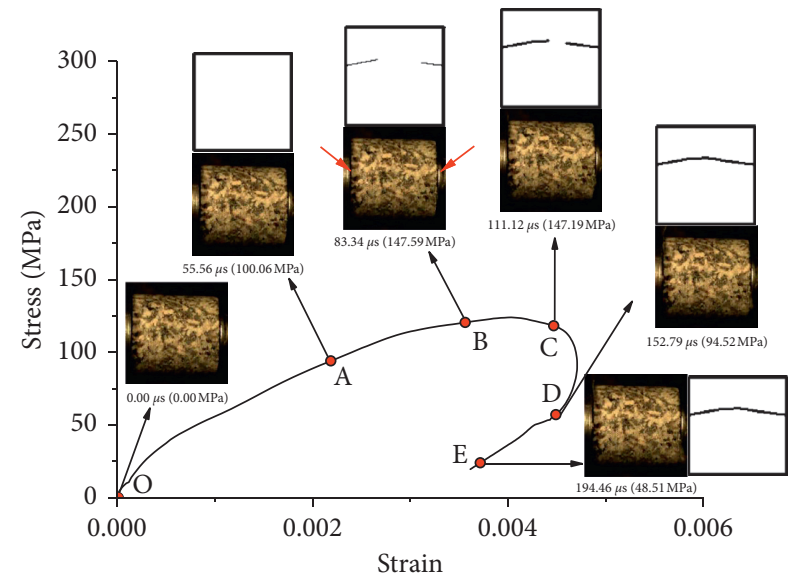

(b)

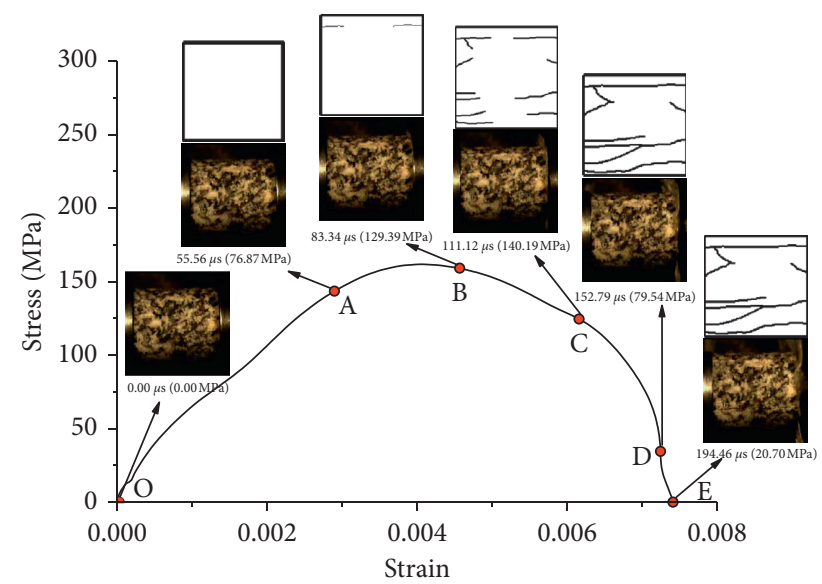

(d)

FIGURE 7: Stress-time and stress-strain curves of type II and III specimens with photos by high-speed camera: (a), (b) specimen G-8 in type II; (c), (d) specimen G-13 in type III.

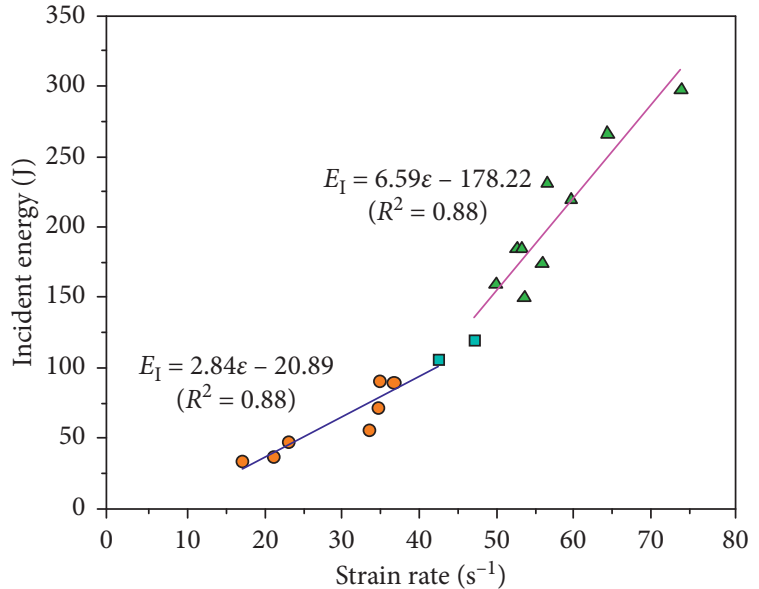

- Unruptured state

- Ruptured state

$\Delta$ Fragmented state
- Fitting linear of unruptured state

- Fitting linear of fragmented state

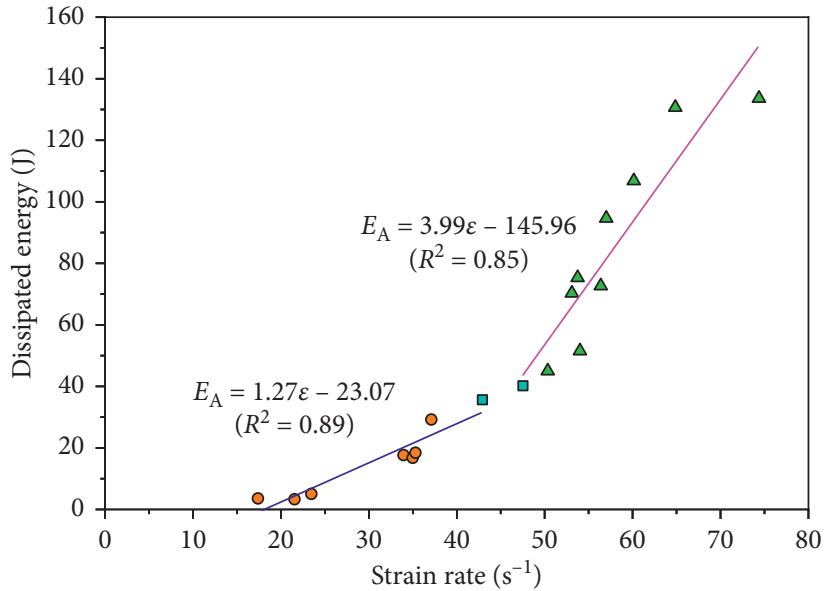

- Unruptured state

a Ruptured state

$\Delta$ Fragmented state

- Fitting linear of unruptured state Fitting linear of fragmented state

(a)

(b)

Figure 8: Continued. 


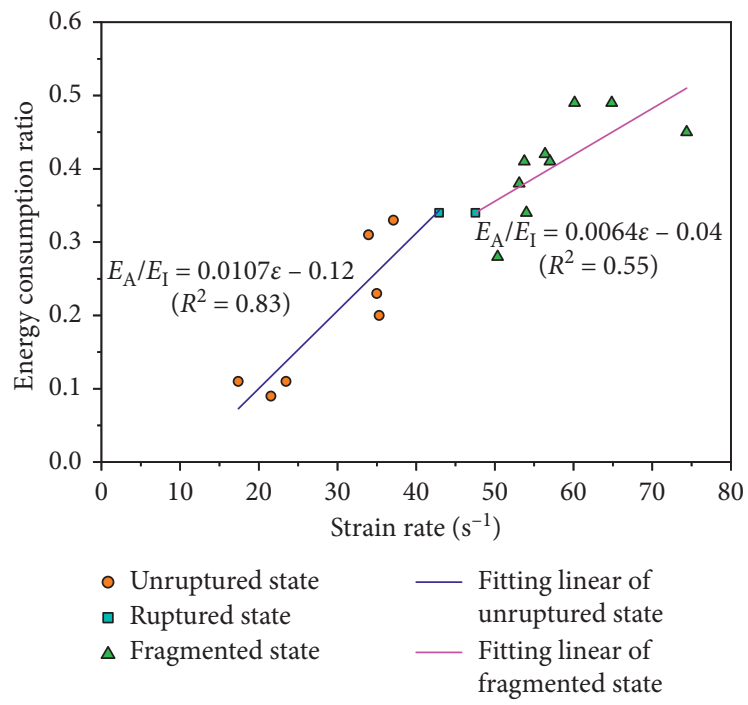

(c)

FIGURE 8: Strain rate versus incident energy. (a) Dissipated energy (b) and energy consumption ratio (c).

TABLE 2: Incident energy, dissipated energy, and energy consumption ratio based on measurement.

\begin{tabular}{|c|c|c|c|c|c|c|}
\hline $\begin{array}{l}\text { Specimen } \\
\text { number }\end{array}$ & $\begin{array}{l}\text { Air pressure } \\
(\mathrm{MPa})\end{array}$ & $\begin{array}{l}\text { Strain rate } \\
\qquad\left(\mathrm{s}^{-1}\right)\end{array}$ & $\begin{array}{c}\text { Consumption } \\
\text { ratio }\left(E_{\mathrm{A}} / E_{\mathrm{I}}(\%)\right)\end{array}$ & $\begin{array}{c}\text { Incident energy } \\
E_{\mathrm{I}}(\mathrm{J})\end{array}$ & $\begin{array}{c}\text { Dissipated energy } \\
E_{\mathrm{A}}(\mathrm{J})\end{array}$ & $\begin{array}{c}\text { States after } \\
\text { impact }\end{array}$ \\
\hline G-1 & 0.35 & 17.38 & 0.11 & 33.82 & 3.57 & Unruptured \\
\hline G-2 & 0.37 & 21.54 & 0.09 & 37.07 & 3.28 & Unruptured \\
\hline G-3 & 0.40 & 23.47 & 0.11 & 47.93 & 5.06 & Unruptured \\
\hline G-4 & 0.43 & 33.95 & 0.31 & 56.70 & 17.66 & Unruptured \\
\hline G-5 & 0.46 & 34.99 & 0.23 & 72.39 & 16.78 & Unruptured \\
\hline G-6 & 0.50 & 37.11 & 0.33 & 89.50 & 29.20 & Unruptured \\
\hline G-7 & 0.50 & 35.30 & 0.20 & 90.45 & 18.40 & Unruptured \\
\hline G-8 & 0.53 & 42.92 & 0.34 & 106.17 & 35.65 & Ruptured \\
\hline G-9 & 0.55 & 47.54 & 0.34 & 119.87 & 40.20 & Ruptured \\
\hline G-10 & 0.57 & 54.02 & 0.34 & 149.62 & 51.49 & Fragmented \\
\hline G-11 & 0.60 & 50.36 & 0.28 & 159.11 & 44.99 & Fragmented \\
\hline G-12 & 0.63 & 56.38 & 0.42 & 174.10 & 72.65 & Fragmented \\
\hline G-13 & 0.65 & 53.75 & 0.41 & 184.57 & 75.32 & Fragmented \\
\hline G-14 & 0.65 & 53.10 & 0.38 & 184.70 & 70.28 & Fragmented \\
\hline G-15 & 0.70 & 60.13 & 0.49 & 219.01 & 106.81 & Fragmented \\
\hline G-16 & 0.75 & 57.01 & 0.41 & 230.94 & 94.63 & Fragmented \\
\hline G-17 & 0.80 & 64.86 & 0.49 & 266.18 & 130.65 & Fragmented \\
\hline G-18 & 0.83 & 74.38 & 0.45 & 296.92 & 133.60 & Fragmented \\
\hline
\end{tabular}

increasing incident energy. Note that all or most fine particles are included in 5\% mass passing, the result for $5 \%$ mass passing is important for fines in rock fragmentation.

\section{Discussion}

4.1. Critical Incident Energy. The critical incident energy should be very useful for practical rock destruction such as percussive rock drilling, rock blasting, rock crushing, and ore grinding. As incident energy is smaller than the critical incident energy, most of the incident energy will be released due to elastic rebound, and part of the incident energy used in creating internal damage or microcracking is little. Therefore, in practical operation for rock destruction, the tested incident energy must be greater than the critical incident energy. This study shows that the critical incident energy is from $106 \mathrm{~J} / \mathrm{V}$ to $120 \mathrm{~J} / \mathrm{V}$. In rock blasting, a specific charge in mining and tunneling is often from 0.3 to $1.2 \mathrm{~kg} / \mathrm{m}^{3}$ (Zhang [24]). Assuming that the explosion energy of a commercial explosive is $4 \mathrm{MJ} / \mathrm{kg}$ and this explosion energy can be taken as the incident energy in blasting, we may find that, in rock blasting, about $1.2-4.8 \mathrm{MJ}$ incident energy is used per square meter of rock. This is much greater than 106-120 J/V. The above discussion indicates that it is important to investigate the critical incident energy further and explore the applications of this critical incident energy to rock blasting since the quantity of the tests in this study is limited. 


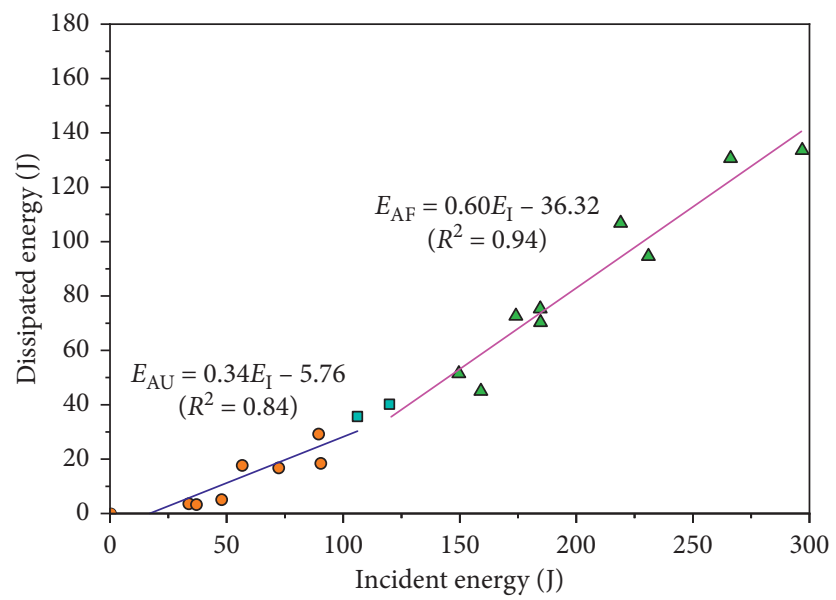

$\begin{array}{ll}- \text { Unruptured state } & \text { Fitting linear of unruptured } \\ \text { - Ruptured state } & \text { state } \\ \Delta \text { Fragmented state } & \text { Fitting linear of fragmented } \\ & \text { state }\end{array}$

FIGURE 9: Incident energy versus dissipated energy of specimens under the three rupture states.
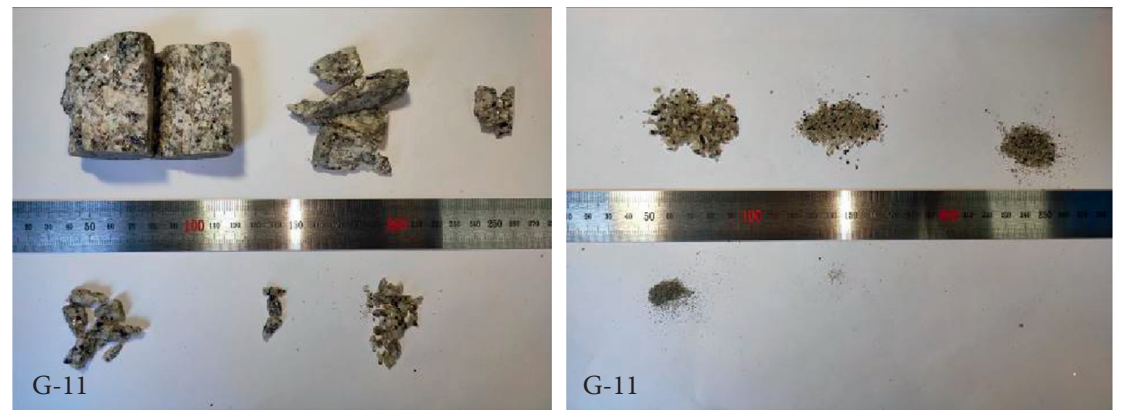

(a)
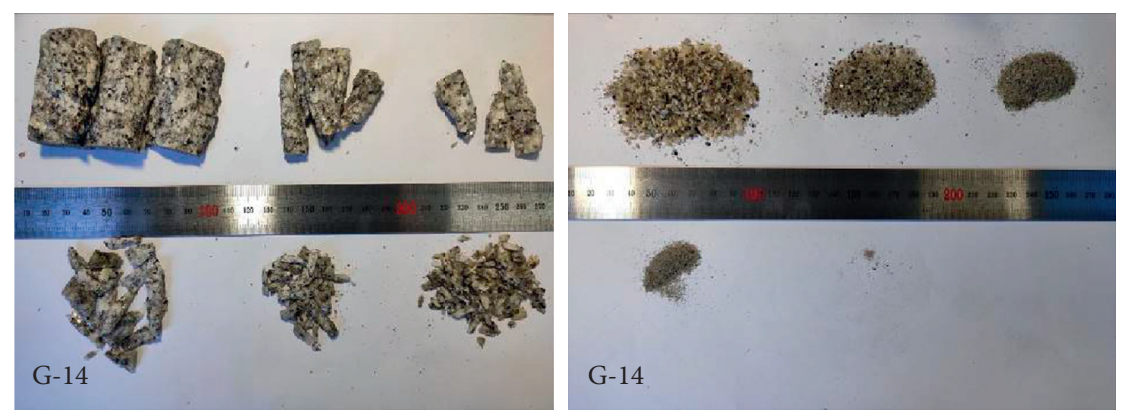

(b)
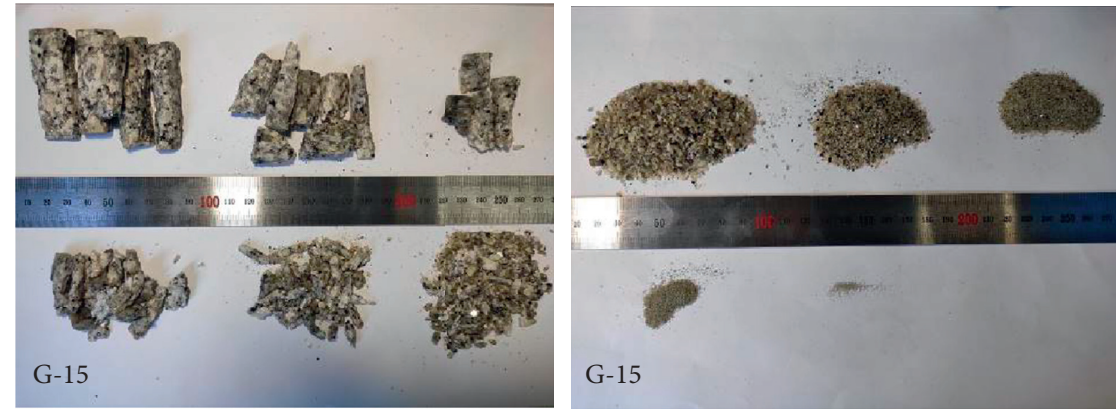

(c)

Figure 10: Continued. 

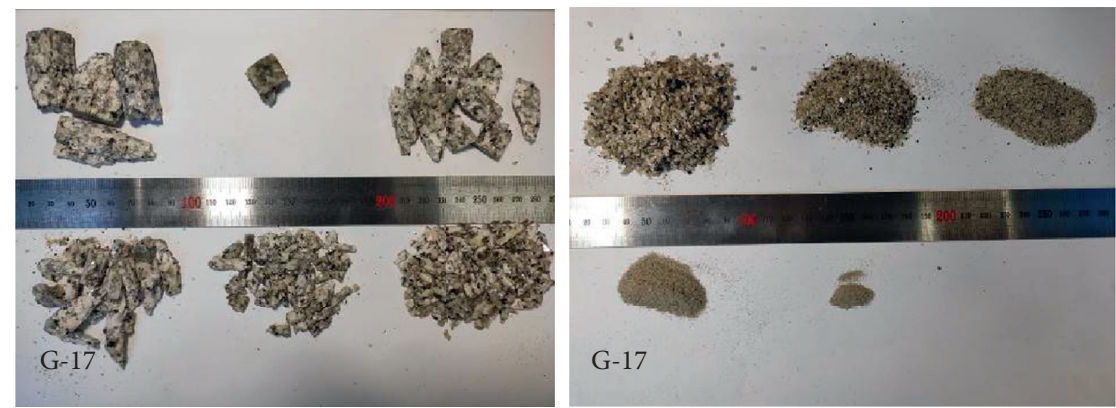

(d)
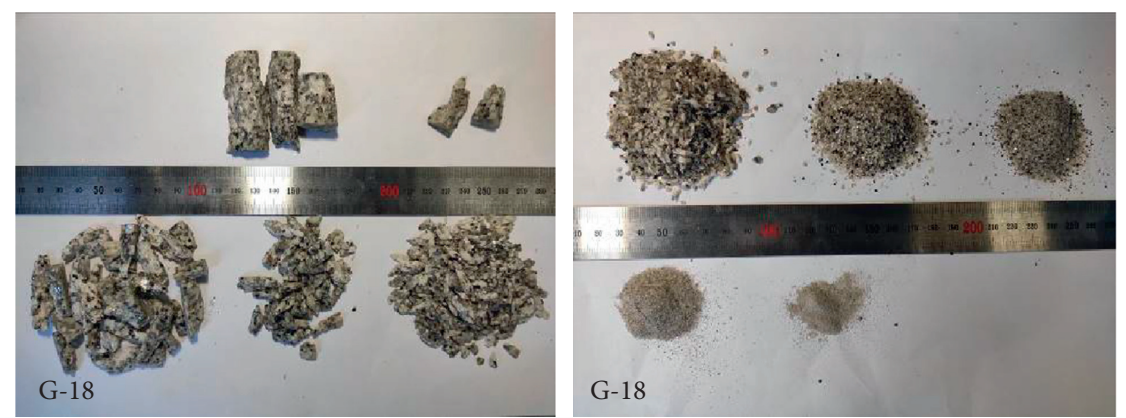

(e)

FIGURE 10: Fragments at different mesh sizes: (a-e) specimens G-11, G-14, G-15, G-17, and G-18.

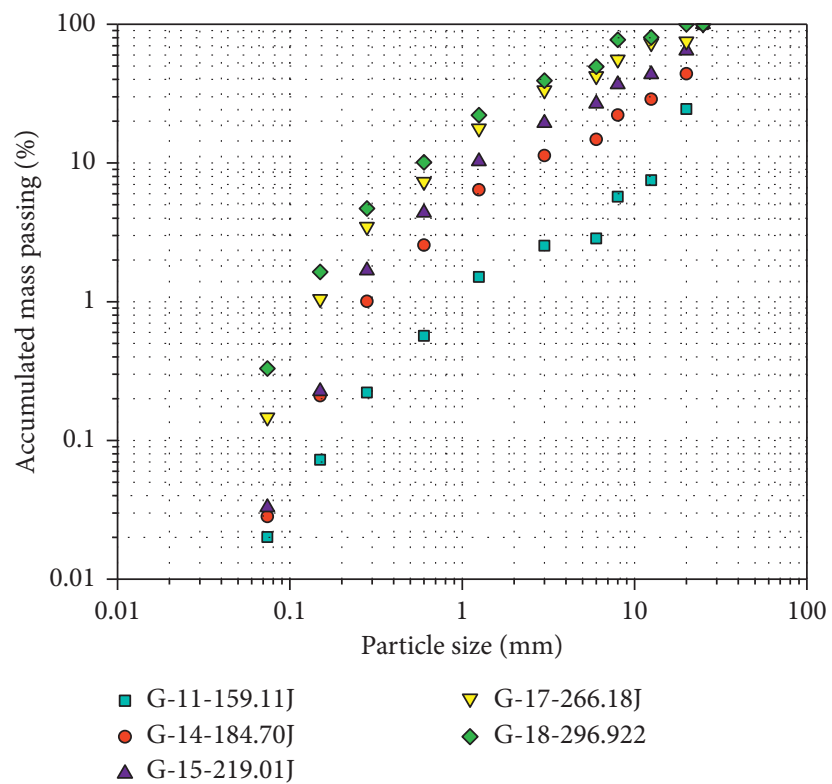

Figure 11: Accumulated mass passing (\%) versus particle size $(\mathrm{mm})$ in the coordinate of log.

4.2. Energy Efficiency. Dissipated energy and energy consumption ratio increase with increasing strain rate. This does not mean that energy efficiency (the ratio of energy used in rock fracture to incident energy or input energy) increases with increasing strain rate because we do not know how much the kinetic energy and other energies are. In dynamic rock fracture tests by Zhang et al. [22], kinetic energy was determined and they found that the energy efficiency decreases with increasing loading rate. In dynamic compression tests, it is very difficult to determine the kinetic energy carried by flying fragments since they are many and in various sizes. Therefore, this is an issue to be studied in the future. 
TABLE 3: Mass of fragments remained on each sieve.

\begin{tabular}{|c|c|c|c|c|c|}
\hline \multirow{2}{*}{ Sieve size $(\mathrm{mm})$} & \multicolumn{5}{|c|}{ Mass of fragments remained on each sieve $(\mathrm{g})$} \\
\hline & Specimen G-11 & Specimen G-14 & Specimen G-15 & Specimen G-17 & Specimen G-18 \\
\hline 0.074 & 0.05 & 0.07 & 0.08 & 0.35 & 0.79 \\
\hline 0.15 & 0.13 & 0.45 & 0.47 & 2.15 & 3.13 \\
\hline 0.28 & 0.37 & 1.97 & 3.53 & 5.80 & 7.33 \\
\hline 0.60 & 0.86 & 3.85 & 6.57 & 9.20 & 12.95 \\
\hline 1.25 & 2.34 & 9.54 & 14.32 & 24.96 & 28.69 \\
\hline 3.00 & 2.54 & 12.13 & 22.16 & 37.51 & 40.99 \\
\hline 6.00 & 0.80 & 8.63 & 17.93 & 21.27 & 24.39 \\
\hline 8.00 & 7.12 & 18.26 & 24.43 & 32.12 & 66.59 \\
\hline 12.50 & 4.45 & 16.57 & 16.43 & 41.38 & 7.16 \\
\hline 20.00 & 42.11 & 37.31 & 51.03 & 5.04 & 47.27 \\
\hline 25.00 & 187.72 & 138.80 & 86.14 & 59.23 & 0.00 \\
\hline
\end{tabular}

TABLE 4: Mass of specimens before and after test.

\begin{tabular}{lccc}
\hline Specimen number & Mass before test $(\mathrm{g})$ & Mass after test $(\mathrm{g})$ & Weight loss $(\%)$ \\
\hline G-11 & 250.00 & 248.49 & 0.6 \\
G-14 & 253.00 & 247.58 & 2.1 \\
G-15 & 251.00 & 243.09 & 3.2 \\
G-17 & 252.00 & 239.01 & 5.2 \\
G-18 & 253.00 & 239.29 & 5.4 \\
\hline
\end{tabular}

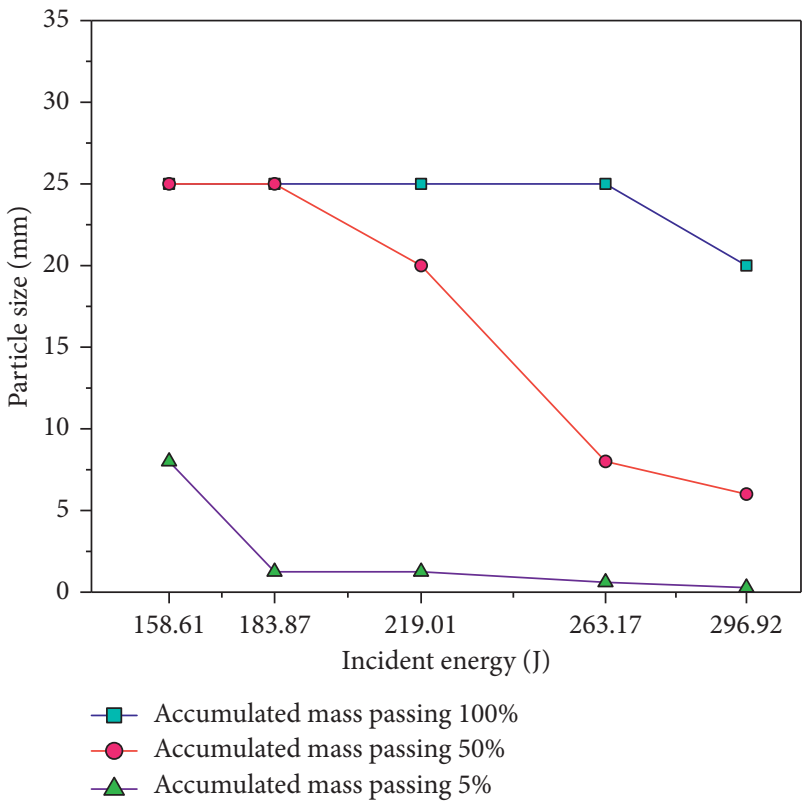

FIgURe 12: Particle size (mm) versus incident energy (J).

\section{Conclusions}

Based on the dynamic compression tests of granite specimens under different incident energies by using an SHPB testing system, the following conclusions can be drawn:

(1) Under the impact of different incident energy, three states appear in the dynamic compression tests of the granite specimens, unruptured state, ruptured state, and fragmented state. These three states correspond to three different types of stress-strain curves.
(2) There exists critical incident energy in dynamic rock compassion tests. As the incident energy is smaller than the critical incident energy, the rock will not be fractured, that is, unruptured; as incident energy is greater than the critical incident energy, the rock will be fractured or fragmented into different-size fragments. In this study, the critical incident energy is found to be approximately $106-120 \mathrm{~J}$, namely, $0.29-0.33 \mathrm{MJ} / \mathrm{m}^{3}$.

(3) Taking the critical incident energy as the boundary, there is a linear relationship in two intervals between the dissipated energy and the incident energy, which shows that there is a linear energy dissipation law in the dynamic compression test. When the tested incident energy is less than the critical incident energy, the dynamic compression test and static compression test have similar linear energy dissipation laws.

(4) The energy consumption ratio of a rock specimen, either ruptured or unruptured, increases with increasing strain rate. The energy consumption ratio of an unruptured specimen increases faster than a fragmented specimen.

(5) Fragment sizes at each mesh decrease with an increasing incident energy; that is, fragmentation becomes finer as incident energy increases.

\section{Data Availability}

All data generated or analyzed during this study are included in this published article.

\section{Conflicts of Interest}

The authors declare that they have no conflicts of interest. 


\section{Acknowledgments}

This study was supported by the National Natural Science Foundation of China (Grant no. 41877272), the Fundamental Research Funds for the Central Universities of Central South University (Grant no. 2020zzts716), and the Fundamental Research Funds for the Central Universities of Southeast University (Grant no. 2242020R10023).

\section{References}

[1] J. Zhao, Y. X. Zhou, A. M. Hefny et al., "Rock dynamics research related to cavern development for ammunition storage," Tunnelling And Underground Space Technology, vol. 14, no. 4, pp. 513-526, 1999.

[2] Q. B. Zhang and J. Zhao, "A review of dynamic experimental techniques and mechanical behaviour of rock materials," Rock Mechanics and Rock Engineering, vol. 47, no. 4, pp. 1411-1478, 2014.

[3] X. B. Li, F. Q. Gong, M. Tao et al., "Failure mechanism and coupled static-dynamic loading theory in deep hard rock mining: a review," Journal of Rock Mechanics and Geotechnical Engineering, vol. 9, no. 4, pp. 767-782, 2017.

[4] Z. Y. Liao, J. B. Zhu, K. W. Xia, and C. A. Tang, "Determination of dynamic compressive and tensile behavior of rocks from numerical tests of split Hopkinson pressure and tension bars," Rock Mechanics and Rock Engineering, vol. 49, no. 10, pp. 3917-3934, 2016.

[5] U. S. Lindholm, L. M. Yeakley, and A. Nagy, "The dynamic strength and fracture properties of dresser basalt," International Journal of Rock Mechanics and Mining Sciences \& Geomechanics Abstracts, vol. 11, no. 5, pp. 181-191, 1974.

[6] T. Zhou, J. B. Zhu, and H. P. Xie, "Mechanical and volumetric fracturing behaviour of three-dimensional printing rock-like samples under dynamic loading," Rock Mechanics and Rock Engineering, vol. 53, no. 6, pp. 2855-2864, 2020.

[7] X. J. Hao, L. Yuan, J. Xue et al., "Physical model test and evaluation for the tunnel stability influenced by magnitude and path of loading," Journal of Testing and Evaluation, vol. 48, no. 2, pp. 1452-1477, 2020.

[8] Y. Bernabé and A. Revil, "Pore-scale heterogeneity, energy dissipation and the transport properties of rocks," Geophysical Research Letters, vol. 22, no. 12, pp. 1529-1532, 1995.

[9] D. Huang and Y. R. Li, "Conversion of strain energy in triaxial unloading tests on marble," International Journal of Rock Mechanics and Mining Sciences, vol. 66, no. 1, pp. 160-168, 2014.

[10] M. M. He, F. Pang, H. T. Wang, J. W. Zhu, and Y. S. Chen, "Energy dissipation-based method for strength determination of rock under uniaxial compression," Shock and Vibration, vol. 2020, Article ID 865958, 13 pages, 2020.

[11] S. Luo and F. Q. Gong, "Linear energy storage and dissipation laws during rock fracture under three-point flexural loading," Engineering Fracture Mechanics, vol. 234, Article ID 107102, 2020.

[12] H. Munoz, A. Taheri, and E. K. Chanda, "Rock drilling performance evaluation by an energy dissipation based rock brittleness index," Rock Mechanics and Rock Engineering, vol. 49, no. 8, pp. 3343-3355, 2016.

[13] S. Luo and F. Q. Gong, "Linear energy storage and dissipation laws of rocks under preset angle shear conditions," Rock Mechanics and Rock Engineering, vol. 53, no. 7, pp. 33033323, 2020.
[14] X. S. Liu, J. G. Ning, Y. L. Tan, and Q. H. Gu, "Damage constitutive model based on energy dissipation for intact rock subjected to cyclic loading," International Journal of Rock Mechanics and Mining Sciences, vol. 85, pp. 27-32, 2016.

[15] A. V. Mikhalyuk and V. V. Zakharov, "Dissipation of dynamic-loading energy in quasi-elastic deformation processes in rocks," Journal of Applied Mechanics and Technical Physics, vol. 38, no. 2, pp. 312-318, 1997.

[16] L. Gao, F. Gao, Z. Z. Zhang, and Y. Xing, "Research on the energy evolution characteristics and the failure intensity of rocks," International Journal of Mining Science and Technology, vol. 30, no. 5, pp. 705-713, 2020.

[17] F. Q. Gong, J. Y. Yan, S. Luo, and X. B. Li, "Investigation on the linear energy storage and dissipation laws of rock materials under uniaxial compression," Rock Mechanics and Rock Engineering, vol. 52, no. 12, pp. 4237-4255, 2019.

[18] F. Q. Gong, S. Luo, and J. Y. Yan, "Energy storage and dissipation evolution process and characteristics of marble in three tension-type failure tests," Rock Mechanics and Rock Engineering, vol. 51, no. 11, pp. 3613-3624, 2018.

[19] F. Q. Gong, J. Y. Yan, X. B. Li, and S. Luo, “A peak-strength strain energy storage index for rock burst proneness of rock materials," International Journal of Rock Mechanics and Mining Sciences, vol. 117, pp. 76-89, 2019.

[20] B. Lundberg, "A split Hopkinson bar study of energy absorption in dynamic rock fragmentation," International Journal of Rock Mechanics and Mining Sciences \& Geomechanics Abstracts, vol. 13, no. 6, pp. 187-197, 1976.

[21] X. B. Li, Impact Rock Dynamics, Changsha: Press of SouthCentral University of Technology, Changsha, China, 1994.

[22] Z. X. Zhang, S. Q. Kou, L. G. Jiang, and P.-A. Lindqvist, "Effects of loading rate on rock fracture: fracture characteristics and energy partitioning," International Journal of Rock Mechanics and Mining Sciences, vol. 37, no. 5, pp. 745-762, 2000.

[23] Z. X. Zhang, J. Yu, S. Q. Kou, and P.-A. Lindqvist, "Effects of high temperatures on dynamic rock fracture," International Journal of Rock Mechanics and Mining Sciences, vol. 38, no. 2, pp. 211-225, 2001.

[24] Z. X. Zhang, Rock Fracture and Blasting: Theory and Applications, Oxford: Elsevier/Butterworth-Heinemann, Oxford, UK, 2016.

[25] X. B. Li, T. S. Lok, and J. Zhao, "Dynamic characteristics of granite subjected to intermediate loading rate," Rock Mechanics and Rock Engineering, vol. 38, no. 1, pp. 21-39, 2005.

[26] L. Hong, Z. L. Zhou, T. B. Yin, G. Y. Liao, and Z. Y. Ye, "Energy consumption in rock fragmentation at intermediate strain rate," Journal of Central South University of Technology, vol. 16, no. 4, pp. 677-682, 2009.

[27] Y. Deng, M. Chen, Y. Jin, and D. W. Zou, “Theoretical analysis and experimental research on the energy dissipation of rock crushing based on fractal theory," Journal of Natural Gas Science and Engineering, vol. 33, pp. 231-239, 2016.

[28] F. Q. Gong and J. Hu, "Energy dissipation characteristic of red sandstone in the dynamic Brazilian disc test with SHPB setup," Advances in Civil Engineering, vol. 2020, Article ID 7160937, 10 pages, 2020.

[29] T. S. Lok, X. B. Li, D. Liu, and P. J. Zhao, “Testing and response of large diameter brittle materials subjected to high strain rate," Journal of Materials in Civil Engineering, vol. 14, no. 3, pp. 262-269, 2002.

[30] Y. X. Zhou, K. Xia, X. B. Li et al., "Suggested methods for determining the dynamic strength parameters and mode-I fracture toughness of rock materials," International Journal of 
Rock Mechanics and Mining Sciences, vol. 49, pp. 105-112, 2012.

[31] J. C. Li, L. F. Rong, H. B. Li, and S. N. Hong, "An SHPB test study on stress wave energy attenuation in jointed rock masses," Rock Mechanics and Rock Engineering, vol. 52, no. 2, pp. 403-420, 2019.

[32] F. Q. Gong, H. Ye, and Y. Luo, "The effect of high loading rate on the behaviour and mechanical properties of Coal-Rock combined body," Shock and Vibration, vol. 2018, Article ID 4374530, 9 pages, 2018.

[33] F. Dai, S. Huang, K. Xia, and Z. Tan, "Some fundamental issues in dynamic compression and tension tests of rocks using split Hopkinson pressure bar," Rock Mechanics and Rock Engineering, vol. 43, no. 6, pp. 657-666, 2010.

[34] S. Luo and F. Q. Gong, "Experimental and numerical analyses of the rational loading waveform in SHPB test for rock materials," Advances in Civil Engineering, vol. 2018, Article ID 3967643, 13 pages, 2018.

[35] F. Q. Gong, X. F. Si, X. B. Li, and S. Y. Wang, "Dynamic triaxial compression tests on sandstone at high strain rates and low confining pressures with split Hopkinson pressure bar," International Journal of Rock Mechanics and Mining Sciences, vol. 113, pp. 211-219, 2019.

[36] X. F. Si, F. Q. Gong, X. B. Li, S. Wang, and S. Y. Luo, "Dynamic Mohr-Coulomb and Hoek-Brown strength criteria of sandstone at high strain rates," International Journal of Rock Mechanics and Mining Sciences, vol. 115, pp. 48-59, 2019.

[37] F. Q. Gong, "Experimental study of rock mechanical properties under coupled static dynamic loads and dynamic strength criterion," Ph.D. thesis, China: Central South University, Changsha, China, 2010.

[38] H. P. Xie, L. Y. Li, R. D. Peng, and Y. Ju, "Energy analysis and criteria for structural failure of rocks," Journal of Rock Mechanics and Geotechnical Engineering, vol. 1, no. 1, pp. 11-20, 2009. 